\title{
ASPECTOS SANITÁRIOS E DE MANEJO EM CRIAÇÕES DE CAPRINOS E OVINOS NA MICRORREGIÃO DE PATOS, REGIÃO SEMI-ÁRIDA DA PARAÍBA
}

\author{
Tásia Cortês Pereira dos Santos ${ }^{1}$, Carlos Enrique Peña Alfaro ${ }^{2}$, Salomão Moreira de Figueiredo ${ }^{1}$
}

1. Mestrandos em Medicina Veterinária, UAMV/CSTR/UFCG/Campus de Patos - santostasia@hotmail.com 2. Médico Veterinário, Professor da UFCG, Doutor em Reprodução Animal.

\section{RESUMO}

Com objetivo de identificar as características relacionadas aos sistemas de criação caprina e ovina na Microrregião de Patos-PB, semi-árido da Paraíba, foram analisadas 90 propriedades de nove municípios da região do Sertão do Estado da Paraíba. Foram aplicados questionários visando a obter informações relacionadas aos siste- mas de criação caprina e ovina, envolvendo aspectos sanitários, nutricionais, produtivos e reprodutivos. Os resultados mostraram que o sistema extensivo é predominante e, associado às práticas de manejo nutricional e reprodutivo deficientes, tem contribuído para baixos índices de produção.

PALAVRAS-CHAVE: semi-árido; caprinos; ovinos; sistemas produtivos.

\section{SANITARY AND MANAGEMENT ASPECTS OF GOAT AND OVINE FARM IN THE MICRO-REGION OF PATOS IN THE SEMI-ARID AREA OF PARAIBA STATE}

The aim of this study was to identify several characteristics related to the systems of goat and ovine production in the region of Patos-PB. A total of 90 properties located in the semi-arid region of the Paraiba State were analyzed, by means of questionnaires aiming at getting information

KEYWORDS: semi-arid; goat; ovine; production systems.

\section{INTRODUÇÃO}

O Nordeste do Brasil possui $1.560 .000 \mathrm{~km}^{2}$ de superfície, representando $18 \%$ da área total do related to the systems of goat and ovine production, involving sanitary, nutrition, productive and reproductive aspects. It could be concluded that the extensive management is predominant with unsatisfactory nutrition and reproductive aspects leading to low production rates.

país. Destes, $75 \%$ estão inseridos na região Semiárida, o que representa $9,5 \%$ da área geográfica nacional, totalizando $850.000 \mathrm{Km}^{2}$, com grande concentração de rebanhos caprinos e ovinos que 
desempenham importante papel sócio-econômico (IBGE, 2006).

Os sistemas de produção caprina e ovina na região têm se caracterizado por apresentar baixos índices produtivos em decorrência, principalmente, de práticas de manejo inadequado, más condições sanitárias, baixa capacidade de investimento, irregularidades na disponibilidade de alimentos ao longo do ano, baixa capacidade de absorção tecnológica pelas propriedades, entre outras (PINHEIRO et al., 2000).

Apesar desse quadro desfavorável, a introdução de animais especializados para leite e carne, verificada na região nos últimos vinte anos, tem despertado um interesse maior por essas espécies, associado à valorização de determinadas raças que vem se expandindo do Nordeste para todo o Brasil, a exemplo da raça ovina Santa Inês (NOGUEIRA, 2007) e a expansão da caprinocultura de leite no Cariri paraibano (RODRIGUES \& QUINTANS, 2007).

A produção de carne e pele de ovinos e caprinos no Brasil apresenta um horizonte de crescimento muito significativo e sem precedentes em outra cultura do agronegócio, pois tanto o mercado interno é extremamente ávido por seus produtos e derivados, como o mercado externo é altamente comprador de carne e de peles (SEBRAE, 2007).

A caprinovinocultura nos últimos anos vem despontando no agronegócio brasileiro como opção de diversificação da produção, gerando, assim, oportunidades de emprego, renda e fixação do homem no campo, demonstrando seu importante papel no contexto da pecuária brasileira. No entanto, ainda é precário o nível de desfrute, produtividade, gerenciamento e articulação do setor primário da cadeia produtiva em questão, dificultando melhorias de competitividade e remuneração dos próprios produtores, ameaçando o pleno desenvolvimento e a sustentabilidade da atividade (SEBRAE, 2007). Ainda segundo esse autor, na ótica do desenvolvimento sustentável, é fundamental a implantação e estruturação de um planejamento estratégico, construído de forma conjunta, na discussão de temas e propostas que possibilitem aos diversos atores da cadeia produtiva novos conhecimentos e tecnologias de produção e gestão dos seus negócios.

BANDEIRA et al. (2007b) afirmaram que as mudanças nas relações comerciais com abertura dos mercados propiciaram à atividade agropecuária uma otimização das suas unidades produtivas, tornando-as mais competitivas, fazendo com que al- guns produtores de caprinos fossem estimulados a buscar maior eficiência produtiva para atender à demanda regional e internacional. Diversos trabalhos têm mostrado os aspectos de manejo, sanidade e nutrição aplicados aos sistemas de produção caprina e ovina em diferentes regiões do Nordeste (PINHEIRO et al., 2000; PEDROSA et al., 2003; BANDEIRA et al., 2007a; BANDEIRA et al., 2007b; SEBRAE 2007; COSTA et al., 2008).

Os estudos sobre as condições de criação nas diversas regiões são importantes para analisar as particularidades que cada região apresenta, possibilitando, assim, estabelecer ações que visem à melhoria das mesmas e, de acordo com NOGUEIRA (2007), ter uma mudança de paradigmas no enfoque da realidade das especificidades do semi-árido.

Nesse contexto, com o presente trabalho, objetivou-se analisar as características sanitárias e produtivas dos sistemas de produção caprina e ovina em municípios que compõem a Microrregião de PatosPB.

\section{MATERIAL E MÉTODOS}

Foram coletados dados de propriedades de nove municípios que integram a Microrregião de Patos, mesorregião do sertão paraibano. Os municípios estudados foram: Areia de Baraúnas, Cacimba de Areia, Mãe D’Água, Passagem, Quixabá, Patos, Santa Terezinha, São José das Espinharas e São José do Bonfim. Os municípios abrangem uma superfície de $2269,11 \mathrm{Km}^{2}$.

No período compreendido entre julho e dezembro de 2007, dez propriedades de cada município integrante da microrregião foram selecionadas aleatoriamente, num total de 90 propriedades. A coleta de informações foi feita utilizando-se um questionário contendo 100 perguntas relacionadas com o manejo geral e com o manejo sanitário, nutricional e reprodutivo.

A seleção das propriedades foi realizada por meio das recomendações de REIS (2003) usando-se a amostragem por área. Os dados foram coletados através de entrevista direta com o proprietário ou responsável e em visitas às propriedades rurais previa e aleatoriamente selecionadas a partir de cadastro de órgãos de assistência técnica e fomento. Os dados coletados foram tabulados e analisados separadamente. Para caracterização das formas de produção das criações de caprinos e ovinos, utilizaram-se as respostas obtida nas entrevistas com os produtores e realizada a distribuição de freqüências das principais 
características relacionadas com o produtor, propriedade e rebanho, a saber: práticas de manejo reprodutivo adotadas, tipo de vacina e número de vacinações utilizadas, principais medidas sanitárias e principais problemas sanitários nos rebanhos relatados pelo produtor.

\section{RESULTADOS E DISCUSSÃO}

A frequência das atividades de manejo geral nas propriedades esta apresentada na Tabela 1. Verifica-se que a atividade de identificação dos animais é baixa, situando-se em níveis abaixo de $35 \%$ das propriedades, o que reflete diretamente o grau de organização encontrado na região, já que a escrituração zootécnica constitui uma das ações fundamentais para a boa prática administrativa das propriedades, possibilitando com isso um manejo adequado, um melhor controle dos animais e uma seleção eficiente. $\mathrm{Na}$ região Norte e Nordeste de Minas Gerais, em dados publicados em ANÁLISE DA OVINOCAPRINOCULTURA... (2004), foram encontrados valores semelhantes aos obtidos no presente trabalho. NOGUEIRA \& MELLO (2005) verificaram baixo percentual de escrituração zootécnica em criações de caprinos na região Sudoeste do Estado de São Paulo. Esses resultados vêm a corroborar as observações de COSTA et al. (2008) que, num estudo na região do Cariri paraibano, observaram falta de escrituração zootécnica nos rebanhos. Quanto à prática de pesagem dos animais, os valores observados neste trabalho são considerados muito baixos, uma vez que menos de $5 \%$ das propriedades realizavam essa prática após o nascimento dos animais.

Com relação à utilização de práticas de manejo de animais, verificou-se que em menos de $22 \%$ das propriedades nenhuma prática era aplicada, deixando-se os animais em regime extensivo. Ao analisar a separação dos animais por categoria (jovens e adultos), os percentuais aqui observados $(22,5 \%)$ foram superiores àqueles verificados na região Norte $(15,7 \%)$ e Nordeste $(5,3 \%)$ do Estado de Minas Gerais, dados publicados em ANÁLISE DA OVINOCAPRINOCULTURA... (2004). Verificou-se que, na região, o manejo aplicado aos rebanhos reflete diretamente a predominância do sistema de criação extensivo com poucas atividades de manejo, o que contribui para a apresentação dos baixos índices de produtividade observados. Essas observações coincidem com os resultados de PINHEIRO et al. (2000) e PEDROSA et al. (2003) na região Nordes- te e NOGUEIRA \& MELLO (2005) no estado de São Paulo. Já MAGALHÃES et al. (1985), ao analisarem rebanhos nos estados de Rio de Janeiro e Minas Gerais, observaram valores maiores de criações com regime intensivo $(54,2 \%)$.

TABELA 1 - Frequência da utilização de práticas de manejo em criações de caprinos e ovinos na Microrregião de Patos, Mesorregião do Sertão da Paraíba, Patos - 2008

\begin{tabular}{lcc}
\hline MANEJO DO REBANHO & $\begin{array}{c}\text { Frequéncias } \\
\text { (n) }\end{array}$ & $\begin{array}{c}\text { Percentuais } \\
(\%)\end{array}$ \\
\hline Identifica os animais & 32 & 35,95 \\
Anotação dos nascidos & 27 & 30,30 \\
Anotação dos óbitos & 22 & 24,70 \\
Pesa ao nascer & 4 & 4,50 \\
Pesa o/ frequência & 5 & 5,60 \\
Pesa p/ vender & 05 & 5,60 \\
Separa por idade & 20 & 22,50 \\
Separa fêmeas prenhes & 28 & 31,40 \\
Separa fëmeas paridas & 43 & 48,30 \\
Descorna os cabritos & 11 & 12,35 \\
Castra o macho p/ abate & 42 & 47,20 \\
Separa por sexo & 29 & 32,60 \\
Näo utiliza nenhuma prática & 19 & 21,35 \\
\hline
\end{tabular}

Na Tabela 2 verifica-se que os níveis de suplementação com concentrado (45\%), mineralização $(74,15 \%)$, fenação $(18 \%)$ e silagem $(14,6 \%)$ foram inferiores aos observados por BANDEIRA et al. (2007a). É necessário salientar a importância do manejo nutricional para os sistemas de produção caprina e ovina no semi-árido, conforme sugerem PEREIRA et al. (2007), que enfatizam que o desenvolvimento de sistemas de criação no semi-árido deve considerar ações que levem em conta a fragilidade do bioma caatinga quando manejado inadequadamente, as adversidades edafoclimáticas e a necessidade de conservação de recursos naturais.

As categorias animais (jovens e adultos) eram suplementadas de maneira diferente em $18 \%$ das propriedades. O sistema de creep-feeding, que consiste no fornecimento de suplementação alimentar em comedouro seletivo na fase de cria, permitindo somente a entrada das crias, era realizado em $12,35 \%$ das propriedades.

As pastagens nativas eram utilizadas em $100 \%$ das propriedades, e destas $18 \%$ usavam pastagens cultivadas, percentual inferior às observações de BANDEIRA et al. (2007a), que verificaram níveis aproximados de $65 \%$ das criações utilizando 
pastagens cultivadas.

As pastagens encontradas nas 90 propriedades estudadas foram bem diversificadas. Dentre elas pode-se destacar: Capim Andrequicé (Ichnanthus bambusiflorus), Capim Buffel (Cenchrus ciliaris), Capim Corrente (Urochloa mosambicensis), Capim Elefante (Pennisetum purpureum), Capim Paraíso (P. hybridum), Capim Tifton (Cynodon spp.) entre outros, além de gramíneas como as Braquiárias (Brachiaria sp). A grande maioria dos produtores $(84,25 \%)$ utiliza o sistema de pastoreio contínuo enquanto uma pequena parcela $(15,75 \%)$ utiliza o pastoreio rotacionado.

A presença de plantas da caatinga com princípios tóxicos foi bem representativa nas propriedades estudadas, com 52,8\% de ocorrência, sendo as mais encontradas o Tingüí (Mascagnia rígida), Pereiro (Aspidosperma pyrifolium), Maniçoba (Manihot spp.), Anil (Indigofera suffruticosa), Salsa (Ipomoea asarifolia), Angico (Piptadenia macrocarpa), Chocalho-de-cascavel (Crotalaria retusa), Aveloz (Euphorbia tirucalli L.) e Favela (Cnidoscolus phyllacanthus (Euphorbiaceae).

Apenas dois (2,25\%) proprietários utilizavam a técnica de flushing que, segundo OLIVEIRA et al. (2008), consiste numa dieta nutricionalmente mais rica, muito utilizada com o objetivo de aumentar a taxa de ovulação, sendo fornecida em média 30 dias antes do início da estação reprodutiva.

De forma geral, observou-se que as práticas de manejo nutricional verificadas na região não estão em sintonia com a demanda de produção necessária para a obtenção de desempenho produtivo e reprodutivo satisfatórios. Isso está em concordância com as observações de LOPES JUNIOR (2007), que reafirmou a dificuldade de produção de alimentos no semi-árido onde esta realidade é ainda mais marcante e implica cuidados especiais no planejamento alimentar, assim como com as observações de COSTA et al. (2008), que verificaram a falta de manejo alimentar adequado para atender as exigências nutricionais dos animais no Cariri paraibano. No Sudoeste de São Paulo, NOGUEIRA \& MELLO (2005) também constataram que as práticas alimentares nas criações de caprinos e ovinos eram consideradas inadequadas, acarretando um desempenho produtivo insatisfatório.
TABELA 2 - Frequência da utilização de práticas de manejo alimentar em criações de caprinos e ovinos na Microrregião de Patos, Mesorregião do Sertão da Paraíba, Patos - 2008

\begin{tabular}{|c|c|c|}
\hline $\begin{array}{l}\text { PRÁTICAS DE MANEJO } \\
\text { ALIMENTAR }\end{array}$ & $\begin{array}{l}\text { Frequências } \\
\text { (n) }\end{array}$ & $\begin{array}{c}\text { Percentuais } \\
(\%)\end{array}$ \\
\hline Uso de sal mineral & 66 & 74,15 \\
\hline Suplementação na seca & 65 & 73,00 \\
\hline Sal proteinado & 8 & 9,00 \\
\hline Uso de feno & 16 & 18,00 \\
\hline Uso de silagem & 13 & 14,60 \\
\hline Uso de capineira & 13 & 14,60 \\
\hline Uso de cana de açúcar & 5 & 5,60 \\
\hline Uso de ração concentrada & 40 & 45,00 \\
\hline Mistura ração na propriedade & 18 & 20,20 \\
\hline $\begin{array}{l}\text { Suplementação diferenciada } \\
\text { das categorias }\end{array}$ & 16 & 18,00 \\
\hline Usa "Creep-feeding" & 11 & 12,35 \\
\hline Alimentação de órfãos & 87 & 97,75 \\
\hline Usa "Flushing" & 2 & 2,25 \\
\hline Utiliza pastagem nativa & 90 & 100,00 \\
\hline Utiliza pastagem cultivada & 16 & 18,00 \\
\hline Sistema de Pastejo continuo & 75 & 84,25 \\
\hline Sistema de Pastejo rotacional & 14 & 15,70 \\
\hline Irrigação das pastagens & 19 & 21,35 \\
\hline $\begin{array}{l}\text { Adubação de pastagens } \\
\text { cultivadas }\end{array}$ & 19 & 21,35 \\
\hline
\end{tabular}

A Tabela 3 mostra as atividades relacionadas às práticas da reprodução aplicadas nas propriedades. A maioria dos proprietários não utiliza práticas reprodutivas e a frequência observada para algumas práticas de manejo e uso de biotecnologias estava relacionada às propriedades com nível tecnológico médio e elevado. De forma geral, observa-se que o uso de práticas de manejo reprodutivo é baixo, coincidindo com as afirmações de LOPES JUNIOR (2007) e COSTA et al. (2008), que relacionaram a baixa produtividade da exploração de caprinos e ovinos à falta de práticas de manejo produtivo e reprodutivo, provocando uma significativa redução do retorno financeiro ao produtor. Da mesma forma, observações feitas acerca de dados publicados em ANÁLISE DA OVINOCAPRINOCULTURA...

(2004)

demonstraram que, na região Nordeste de Minas Gerais, cerca de $90 \%$ das criações não apresentam práticas reprodutivas efetivas, o que concorre para diminuir o desempenho produtivo dos caprinos e ovinos. 
TABELA 3 - Frequência da utilização de práticas de manejo reprodutivo em criações de caprinos e ovinos na Microrregião de Patos, Mesorregião do Sertão da Paraíba, Patos - 2008

\begin{tabular}{lcc}
\hline $\begin{array}{l}\text { PRÁTICAS DE MANEJO } \\
\text { REPRODUTIO }\end{array}$ & $\begin{array}{c}\text { Frequências } \\
(\mathrm{n})\end{array}$ & $\begin{array}{c}\text { Percentuais } \\
(\%)\end{array}$ \\
\hline Realiza monta controlada & 5 & 5,60 \\
Realiza inseminação artificial & 3 & 3,40 \\
Transferência de embriöes & 2 & 2,25 \\
Realiza estação de monta & 7 & 7,85 \\
Usa rufião & 5 & 5,60 \\
Sincronização de cio & 3 & 3,30 \\
Presença do macho com as & & \\
fêmeas durante o dia todo & 73 & 82,00 \\
& & \\
Acasalamentos consangüineos & 59 & 66,30 \\
Anotação de pai e mãe & 19 & 21,35 \\
\hline
\end{tabular}

Os aspectos clínicos apontados como os que mais acometeram as criações de caprinos e ovinos, segundo as respostas obtidas, são descritos na Tabela 4. Essas observações mostram um percentual de mortalidade mais elevado que os observados por PEDROSA et al. (2003) que realizaram estudos no Rio Grande do Norte e encontraram taxa de mortalidade de $18,4 \%$ e $6,4 \%$ para animais jovens e para adultos, respectivamente, PINHEIRO et al. (2000) que verificaram taxas de $22,8 \%$ para animais jovens e 4,6\% para adultos e RODRIGUES (2005) que encontrou valores de $9 \%$ e $66 \%$ entre animais adultos e jovens.

A alta frequência de verminoses aqui verificada coincide com a maioria dos trabalhos publicados - MAGALHÃES (1985) no Rio de Janeiro e em Minas Gerais e PINHEIRO et al. (2000) no Ceará -, mas difere das observações de BANDEIRA (2007b) no Cariri paraibano, que relatou que isso não foi observado em seu estudo, além de os sinais relacionados à verminose, como diarréia e pneumonia, não serem considerados importantes pelos criadores; devido a isso, esse autor considerou o aborto (65\%), a mamite $(60 \%)$, a linfadenite caseosa $(51,7 \%)$ e a ceratoconjuntivite $(50 \%)$ como as enfermidades de maior relevância, destacando-se as duas primeiras por estarem relacionadas diretamente com a produção de leite.

Quanto a outras doenças, há variações nas suas frequências, mas algumas são comuns: pneumonias, pododermatite e alterações nervosas.
TABELA 4 - Frequência de sinais clínicos relatados por produtores em criações de caprinos e ovinos na Microrregião de Patos, Mesorregião do Sertão da Paraíba, Patos - 2008

\begin{tabular}{lcc}
\hline SINAIS CLINICOS/DOENÇAS & $\begin{array}{c}\text { Frequências } \\
\text { (n) }\end{array}$ & $\begin{array}{c}\text { Percentuais } \\
(\%)\end{array}$ \\
\hline Verminoses/diarréia & 58 & 65,15 \\
Abortos & 50 & 56,20 \\
Mortalidade de cordeiros e & 50 & 56,20 \\
cabritos & 49 & 55,05 \\
Ectoparasitos & 47 & 52,80 \\
Plantas tóxicas & 35 & 39,30 \\
Pneumonia & 34 & 38,20 \\
Ceratoconjuntivite & 25 & 28,1 \\
Mastite & 23 & 25,85 \\
Pododermatite & 18 & 20,20 \\
Fotossensibilização & 17 & 19,10 \\
Ectima contagioso/Boqueira & 14 & 15,70 \\
Alterações nervosas & 51 & 57,30 \\
Linfadenite & &
\end{tabular}

O percentual de propriedades com uso de algum tipo de vacinação é verificado na Tabela 5 . O número de estabelecimentos que realizavam vacinação $(78,65 \%)$ pode ser considerado satisfatório quando comparado às observações de RODRIGUES et al. (2005), que realizaram estudos no Sudoeste Paulista e verificaram que pouco mais de $50 \%$ das propriedades realizavam vacinações contra algum tipo de doença. Estudos realizados por CALDAS et al. (1989) no Estado da Bahia revelaram índices abaixo de $10 \%$ de propriedades com vacinações, demonstrando uma situação menos favorável. Observou-se que os dados da Microrregião de Patos apresentam valores superiores aos obtidos nas regiões citadas, embora ainda sejam considerados valores baixos para a prática profilática. A vacina contra raiva era a mais frequentemente utilizada $(71,91 \%)$, seguida pela da febre aftosa $(39,32 \%)$ e clostridioses $(23,6 \%)$. Já as observações de BANDEIRA et al. (2007b) mostraram que a mais frequente foi a vacina contra clostridioses $(95,3 \%)$, seguida da raiva $(65,1 \%)$ e linfadenite caseosa $(30,2 \%)$.

Quanto à prática da vermifugação, os dados aqui verificados (Tabela 5) são menores do que os relatados por PEDROSA et. al. (2003) que observaram que $100 \%$ dos proprietários usavam anti-helmínticos na região Noroeste do Rio Grande do Norte. Da mesma forma, a frequência da vermifugação anual foi menor no presente estudo. Já 
as observações de MAGALHÃES assemelham-se aos do estudo apresentado.

TABELA 5 - Práticas de manejo sanitário em criações de caprinos e ovinos na Microrregião de Patos, Mesorregião do Sertão da Paraíba, Patos 2008

\begin{tabular}{|c|c|c|}
\hline $\begin{array}{l}\text { PRÁTICAS DE MANEJO } \\
\text { SANITÁRIO }\end{array}$ & $\begin{array}{l}\text { Frequências } \\
\text { (n) }\end{array}$ & $\begin{array}{c}\text { Percentuais } \\
(\%)\end{array}$ \\
\hline \multicolumn{3}{|c|}{ Vacinações } \\
\hline Um ou mais tipos de vacinas & 70 & 78,65 \\
\hline Nenhuma vacina & 19 & 21,35 \\
\hline Raiva & 64 & 71,91 \\
\hline Febre Aftosa & 35 & 39,32 \\
\hline Clostridiose & 21 & 23,60 \\
\hline Ectima & 1 & 1,10 \\
\hline Linfadenite & 1 & 1,10 \\
\hline \multicolumn{3}{|c|}{ Destino dos animais mortos } \\
\hline Deixa no pasto & 4 & 4,50 \\
\hline Queima & 33 & 37,10 \\
\hline Coloca no pasto distante & 42 & 47,20 \\
\hline Enterra & 13 & 14,60 \\
\hline Necropsia & 3 & 3,37 \\
\hline Queima e enterra & 3 & 3,37 \\
\hline \multicolumn{3}{|c|}{ Vermifugação } \\
\hline Todas as categorias & 81 & 91,00 \\
\hline Por categorias & 5 & 5,60 \\
\hline \multicolumn{3}{|c|}{ Frequência da Vermifugação } \\
\hline$>4 x /$ ano & 2 & 2,25 \\
\hline $4 x / a n o$ & 15 & 16,85 \\
\hline $3 \mathrm{x} /$ ano & 19 & 21,35 \\
\hline $2 x /$ ano & 36 & 40,45 \\
\hline $1 x /$ ano & 8 & 9,00 \\
\hline Todo mês & 2 & 2,25 \\
\hline Quando apresenta vermes & 4 & 4,50 \\
\hline $\begin{array}{l}\text { Mudança de principio ativo } \\
\text { de vermifugo }\end{array}$ & 35 & 39,32 \\
\hline $\begin{array}{l}\text { Corte e desinfecção do } \\
\text { umbigo }\end{array}$ & 78 & 87,60 \\
\hline
\end{tabular}

\section{CONCLUSÃO}

Concluiu-se que na região semi-árida da Paraíba, ou seja, na região de Patos, as condições de criação dos caprinos e ovinos apresentavam características semelhantes às de outras regiões do Nordeste com predominância de sistemas de manejo de criação extensiva do rebanho em desenvolvimento, condições sanitárias deficientes e uma precariedade na disponibilidade alimentar com reflexos diretos na produtividade das criações. Para essa consolidação faz-se necessária a implantação de ações que melhorem a produtividade das criações caprina e ovina e uma ação mais efetiva dos órgãos responsáveis constituídos para propiciar melhor assistência técnica na região.

\section{REFERÊNCIAS}

ANÁLISE DA OVINOCAPRINOCULTURA NO NORTE E NORDESTE DE MINAS GERAIS. Belo Horizonte: SEBRAE-MG, FAEMG, EMATER-MG. 2004. Disponível em: <http://www.sebraemg.com.br/arquivos/Coopere_para_crescer/geor/diagnostico/ovinocaprinocultura.pdf >. Acessado em: ago 2007.

BANDEIRA, D. A.; CASTRO, R. S.; AZEVEDO, E. O.; MELO, L. S. S.; MELO, C. B. Características de produção da caprinocultura leiteira na região do Cariri na Paraíba. Ciência Veterinária nos Trópicos, v.10, n. 1, p. 29-35, 2007a.

BANDEIRA, D. A.; CASTRO, R. S.; AZEVEDO, E. O.; MELO, L. S. S.; MELO, C. B. Perfil sanitário e zootécnico de rebanhos caprinos nas microrregiões do Cariri paraibano. Arquivo Brasileiro de Medicina Veterinária e Zootecnia, v.59, n.6, p.1597-1600, 2007 b.

CALDAS, E.M.; SANTANA, A.F.; CAETANO, A.L.S. Estudo da ovinocaprinocultura na região Nordeste do Estado da Bahia. Arquivos da Escola de Medicina Veterinária da UFBA, v.12, p.1-98, 1989.

COSTA, R. G.; ALMEIDA, C. C.; PIMENTA FILHO, E. C. HOLANDA JUNIOR, E.V.; SANTOS, N. M. Caracterização do sistema de produção caprino e ovino na região semi-árida do estado da Paraíba. Brasil. Archivos de Zootecnia, v. 57, n. 218, p.195-205, 2008.

INSTITUTO BRASILEIRO DE GEOGRAFIA E ESTATÍSTICA - IBGE, 2006. Disponível em: < http://www.ibge.gov.br >. Acessado em: abr. 2008.

LOPES JÚNIOR, E.S. Manejo reprodutivo de ovinos e caprinos. In: PECNORDESTE - SEMINÁRIO NORDESTINO DE PECUÁRIA, 11, 2007, Fortaleza. Anais... Fortaleza:FAEC, 26p, 2007. Disponível em: $<$ http://www.sheepembryo.com.br/files/artigos/122.pdf> acessado em: jun 2008.

MAGALHÃES H.H. Diagnóstico de situação da caprinocultura em algumas microrregiões dos estados de Minas Gerais e Rio de Janeiro - Resultados Preliminares. Cabras \& Bodes, v.1, p.05-07, 1985.

NOGUEIRA, E.A; MELLO, N.T.D. Diagnóstico sócioeconômico da caprinocultura no sudoeste paulista, Informações Econômicas, São Paulo, v. 35, p. 67-70, n 8. 2005.

NOGUEIRA, F. R. B. Tipologia de sistemas de produção no semi-árido. 2007. 66p; Dissertação (Mestrado em Medicina Veterinária de Pequenos Ruminantes) - Universidade Federal de Campina Grande, Patos - PB, 2007. Disponível em: < http://www.cstr.ufcg.edu.br/ppgmv/dissertacoes/dissert_ii_francisco_roserlandio.pdf $>$. Acessado em: jun 2008.

OLIVEIRA, R. P. M., OLIVEIRA, F. F. Manipulação do ciclo estral em ovinos. PUBVET, v.2, n.7, 2008. Disponível em: < http://www.pubvet.com.br/texto.php?id=146>. Acessado em: mai 2008. 
PEDROSA, K. Y. F.; BARRÊTO JUNIOR, R. A.; COSTA, E. S.; LEITE, A. I.; PAULA, V. V. Aspectos epidemiológicos e sanitários das criações de caprinos e ovinos na zona noroeste do Rio Grande do Norte. Caatinga, Mossoró, v.16, n.1/2, p.17-21, 2003.

PEREIRA, L. G. R.; ARAUJO, G. G. L.; VOLTOLINI, T. V.; BARREIROS, D. C. Manejo Nutricional de Ovinos e Caprinos em Regiões Semi-Áridas. In: PECNORDESTE - SEMINÁRIO NORDESTINO DE PECUÁRIA, 11, 2007, Fortaleza. Anais... Fortaleza: FAEC, 2007. Disponível em: < http://www.infoteca.cnptia.embrapa.br/bitstream/CPATSA/37244/1/OPB1718.pdf>. Acessado em: jul 2008.

PINHEIRO, R. R.; GOUVEIA, A. M. G.; ALVES, F. S. F.; HADDAD, J. P. A. Aspectos epidemiológicos da caprinocultura cearense. Arquivo Brasileiro de Medicina Veterinária e Zootecnia, Belo Horizonte, vol. 52, n.5, p. 534-543, . 2000.

REIS, J. C. Estatística aplicada à pesquisa em ciência veterinária. 1 ed. Olinda: $651 \mathrm{p}, 2003$.
RODRIGUES, R. QUINTANS, L.J. Importância da caprinocultura leiteira para o desenvolvimento dos cariris paraibano. In: PECNORDESTE - SEMINÁRIO NORDESTINO DE PECUÁRIA, 11, 2007, Fortaleza. Anais... Fortaleza: FAEC, 2007. Disponível em: $<$ http://www.pecnordeste.com.br/doc/caprinovionocultura/AldomárioRodrigues.pdf $>$. Acessado em: jun 2008.

RODRIGUES, C. F. C.; MELLO, N. T. C.; LEINZ, F. F.; CARVALHO FILHO, A. C.; BIANCHINI, D.; SANNAZZARO, A. M. Aspectos sanitários da caprinocultura familiar na região Sudoeste Paulista. São Paulo. Arquivos do Instituto Biológico, v. 72, p. 1-64, 2005. Suplemento 2 .

SEBRAE. Perfil Setorial da Caprinocultura no Mundo, Brasil, Nordeste e Sergipe. Sergipe, 2007. Disponível em:<http://www.biblioteca.sebrae.com.br/ bds/BDS.nsf/49A7E70DA9FFD4FA832573840040EE7C /\$File/PERFIL\%20SETORIAL\%20DA\%20 CAPRINOVINOCULTURA.pdf $>$. Acessado em: jun 2008.

Protocolado em: 23 jul. 2008. Aceito em: 11 mar. 2011. 